Gut, 1978, 19, 189-193

\title{
Lymphocytotoxicity test against rabbit hepatocytes in chronic liver diseases
}

\author{
A. FACCHINI ${ }^{1}$, G. F. STEFANINI, M. BERNARDi, F. MIGLIO, \\ G. GASBARRINI, AND G. LABÖ \\ From the Institute of Clinical Medicine I and Pathology III, University of Bologna, Italy
}

SUMMARY We have studied the cytotoxicity against rabbit liver cells of lymphocytes from the peripheral blood of 71 patients with various liver diseases. The group with chronic active hepatitis and three patients with acute alcoholic hepatitis showed significantly higher mean values of lymphocytotoxicity $(P<0.001)$ compared with the other patients with chronic persistent hepatitis, postnecrotic fibrosis and cirrhosis, Wilson's disease, and prolonged viral hepatitis. The mean cytotoxicity of these last groups did not differ significantly from controls. In four out of six patients with chronic active hepatitis a significant decrease of lymphocytotoxicity was found after immunosuppressive therapy with oral prednisolone. A good correlation between the lymphocytotoxicity test and histological signs of activity suggests that a cell-mediated immune aggression is present in this disease.

Some reports (Eddleston and Williams, 1974; Paronetto and Popper, 1976) have stressed the important role of cell-mediated immune aggression against liver cells in the pathogenesis of chronic active hepatitis (CAH). Paronetto and Vernace (1975) have observed a cytotoxic effect of lymphocytes on autochthonous liver cells from patients with CAH. Studies with rabbit hepatocytes (which have a membrane antigen cross-reacting with that found in human hepatocytes (Hopf et al., 1974)), have reached the same conclusion. It was also shown that the lymphocytes responsible for the aggression are confined to the non-T population and are probably $\mathrm{K}$ cells (Cochrane et al., 1976). In addition to the data obtained by in vitro studies, fixed IgG has been demonstrated by Hopf et al. $(1975,1976)$ on the membrane of isolated hepatocytes from patients with $\mathrm{CAH}$, suggesting that antibody-mediated lymphocytotoxicity could be involved. The aim of this work is to study the role of cell-mediated immune aggression against hepatocytes in chronic liver diseases and to consider the possible clinical application of the lymphocytotoxicity test against

\footnotetext{
'Address for correspondence: Dr A. Facchini, Istituto di I Clinica Medica e Gastroenterologia, Laboratorio di Immunologia, Nuove Patologie, Policlinico S. Orsola, Bologna, Italy.

Received for publication 19 September 1977.
}

rabbit hepatocytes.

\section{Methods}

SUBJECTS

In this study 71 patients were examined. Thirty-five (average age 49 years, range 14-76 years), had chronic active hepatitis (CAH), seven (average age 42 years, range 23-66 years) chronic persistent hepatitis (CPH), eight (average age 14 years, range 7-26 years) Wilson's disease (WD), seven (average age 45 years, range 23-66 years) prolonged viral hepatitis (PVH) which lasted from four to 12 months from the onset, three (average age 35 years, range 26-45 years) acute alcoholic hepatitis (AAH), three patients with post-necrotic fibrosis and eight with inactive cirrhosis (average age 49 years, range 37-69 years) were included in the same group $(\mathrm{F} / \mathrm{C})$. The diagnoses were established in each case on the basis of clinical, biochemical, and histological observations. At the time of the study six of 35 with chronic active hepatitis, had received oral 6-methylprednisolone (32 mg per day) for a maximum of 14 days. The group with Wilson's disease had received D-penicillamine (900 $\mathrm{mg}$ per day) for a period from six months to two years previously. Forty-four subjects among the students and the laboratory staff (average age 32 years, range 22-55 years), with no biochemical or clinical signs of hepatic disorders, were taken as controls. 
SEROLOGICAL STUDIES

Routine SGOT, bilirubin, alkaline phosphatase, albumin, gamma-globulins, prothrombin time were carried out by autoanalyser and electrophoresis on cellulose acetate. The presence of $\mathrm{HB}_{\mathrm{s}} \mathrm{Ag}$ was determined by radioimmunoassay (Ausria III25, Abbott). The levels of immunoglobulins $G, A, M$, and of caeruloplasmin (for Wilson's disease) were determined by radial immunodiffusion (Beheringwerke, Marburg). The presence of autoantibodies was determined by immunofluorescence according to Roitt and Doniach (1974). A FITC-labelled anti-human $\mathrm{F}(\mathrm{ab})_{2}, \mathrm{~F} / \mathrm{P}$ molar ratio $=2,1$, was used in this study (Nordic, Tillburg). The antiserum was previously tested on monoclonal bone marrows and shown to react with $\gamma, \mu, \alpha, \kappa$, and $\lambda$, chains (Hijmans et al., 1969). The slides were examined with a Zeiss Universal microscope, equipped with a vertical Plöem's type illuminator. When there was a positive reaction starting from $1: 10$, the serum was diluted till the end point.

\section{LYMPHOCYTOTOXICITY TEST ON RABBIT HEPATOCYTES}

The method of Thompson et al. (1974) was used with the following modifications. All the operations were performed aseptically under a laminar flow bench and all the reagents were sterilised by millipore filtration.

\section{Isolation of hepatocytes}

New Zealand White rabbits, weighing about $500 \mathrm{~g}$ were injected intravenously with a lethal dose of phenobarbitone $(0.5 \mathrm{~g})$ dissolved in $4 \mathrm{ml}$ (5000 U) of heparin (Liquaemin, Roche). A midline incision was made, the liver and the gallbladder were removed, transferred to a Petri dish and washed three times in Dulbecco's phosphate buffered saline (PBS) for five minutes. The liver was then transferred to a Petri dish containing $150 \mathrm{ml}$ of a freshly prepared solution of $0.01 \%$ collagenase (Boheringer Cod. 15412) and 0.1\% hyaluronidase (Sigma Cod. H-2376) in medium A, composed of RPMI 1640-Hepes (Eurobio, Paris), $20 \mathrm{mg} \mathrm{\%}$ gentamicin (Eurobio), $250 \mu \mathrm{g} \%$ amphotericin $\mathrm{B}$ (Eurobio) $+20 \%$ fetal calf serum (Gibco, NY). The liver was cut up in small pieces (1-2 mm) and transferred into a bottle. After overnight incubation at $37^{\circ} \mathrm{C}$, the bottle was inverted and the suspension was left to sediment for 15 minutes at room temperature, the supernatant was aspirated and centrifuged at $200 \mathrm{~g}$ for 10 minutes. The sediment was then washed twice in medium $A$ at 150 and $100 \mathrm{~g}$. The pellet composed of isolated hepatocytes (Fig. 1) was resuspended in $5 \mathrm{ml}$ of medium $\mathrm{A}$ and examined under phase contrast. The viability, determined by

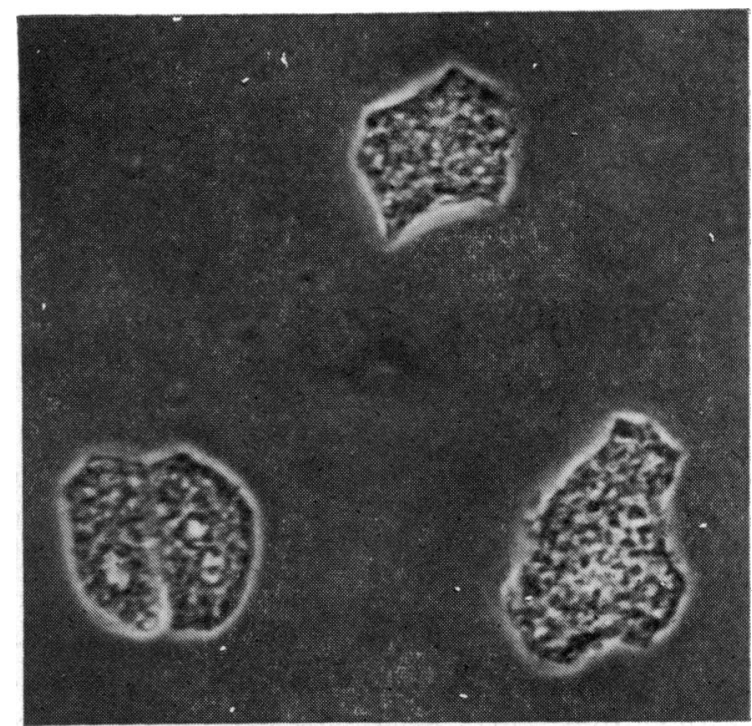

Fig. 1 Isolated hepatocytes adherent to the flasks seen in phase contrast ( $x$ 400).

trypan blue exclusion test, varied between 75 and $92 \%$. The cell suspension $\left(1 \cdot 10^{6}\right.$ hepatocytes $\left./ \mathrm{ml}\right)$ was then transferred into $25 \mathrm{ml}$ disposable flasks (Nunc, Denmark), gassed with $95 \% \mathrm{O}_{2}-5 \% \mathrm{CO}_{2}$ and incubated at $37^{\circ} \mathrm{C}$. These 'stock' flasks were used only for seven days.

\section{Lymphocyte isolation}

Twenty-five millilitres of peripheral blood were defibrinated ( 1 glass bead/ml), $2 \mathrm{mg}$ carbonyl iron were then added, and the suspension was incubated at $37^{\circ} \mathrm{C}$ for 30 minutes with occasional shaking. The blood was diluted 1:1 with PBS and the lymphocytes were obtained using a Ficoll-Hypaque gradient (Böyum, 1968). The cells were washed twice in medium A and brought to a $5 \times 10^{5} / \mathrm{ml}$ concentration.

\section{Preparation of plates}

Eighteen to 24 hours before performing the test, two hepatocyte culture flasks were emptied and the adherent cells collected by washing with medium A. The cell suspension was then centrifuged three times in the same medium ( $150 \mathrm{~g}$ for 20 minutes) and 100 hepatocytes (80-120) in a volume of $10 \mu \mathrm{l}$ were seeded into 60 wells of a Terasaki microtest plate (Falcon 3034). The plates were placed in a humidified box and gassed with the $\mathrm{O}_{2} / \mathrm{CO}_{2}$ mixture. After 18-24 hours' incubation the hepatocytes adhered to the bottom of the wells, the supernatants were gently aspirated and replaced in 30 wells with patient's lymphocyte suspension (hepa- 
tocytes/lymphocytes ration $1 / 500$ ). The other 30 wells were filled with medium $\mathrm{A}$ as controls. The microtest culture plates were gassed with $\mathrm{O}_{2} / \mathrm{CO}_{2}$ and incubated in a humidified atmosphere for 48 hours at $37^{\circ} \mathrm{C}$. The plates were then inverted for two hours, washed gently with warm PBS, fixed with $95 \%$ ethanol for 10 minutes, and stained with $0.1 \%$ eosin in PBS. The number of hepatocytes was counted at $\times 100$ magnification using a graticular eyepiece. The cytotoxicity index \% (CI) was calculated according to the following formula:

$$
\text { CI }(\%)=100-E_{1} / E_{0}
$$

$\mathrm{E}_{1}=$ mean number of adherent hepatocytes in 30 wells after the addition of lymphocytes. $\mathrm{E}_{0}=$ mean number of control hepatocytes ( 30 wells).

The values given are mean $\pm 1 \mathrm{SD}$

Student's $t$ test was performed to estimate the statistical significance between the mean values of the various groups studied. Factorial Fisher's $\chi^{2}$ test was used to estimate the correlation between the cytotoxicity index and the other serological parameters using a Olivetti P652 computer.

\section{Results}

The results of the lymphocytotoxicity test are summarised in Fig. 2.

The group of chronic active hepatitis showed a significantly higher cytotoxicity $(53.8 \pm 14.9)$ when compared with controls $(15.7 \pm 11 \cdot 1, \quad \mathrm{P}<0.001)$ and other groups $(\mathrm{CPH}=8 \cdot 7 \pm 12 \cdot 6, \mathrm{~F} / \mathrm{G}=13 \cdot 3$ $\pm 13 \cdot 3 \mathrm{WD}=26 \cdot 1 \pm 19 \cdot 4, \mathrm{PVH}=21 \cdot 2 \pm 16 \cdot 8$ ).

The cytotoxicity index of these last groups did not significantly $(P<0 \cdot 1)$ differ from controls. The three patients with AAH had the highest cytotoxicity of all groups $(76 \cdot 5 \pm 5 \cdot 5)$. In the group of $\mathrm{CAH}$ patients, the six who had received prednisolone at the time of the study showed a decrease of their CI $(43.3 \pm 16 \cdot 10)$ as compared with the untreated patients $(55.9 \pm 13.8, P<0.05)$. In all groups examined no significant statistical correlation was found between the values of the $\mathrm{CI}$ and the levels of SGOT, SGPT, alkaline phosphatase, prothrombin time, albumin, gamma-globulins, and IgG, A, M. ANA (antinuclear antibodies) were found in

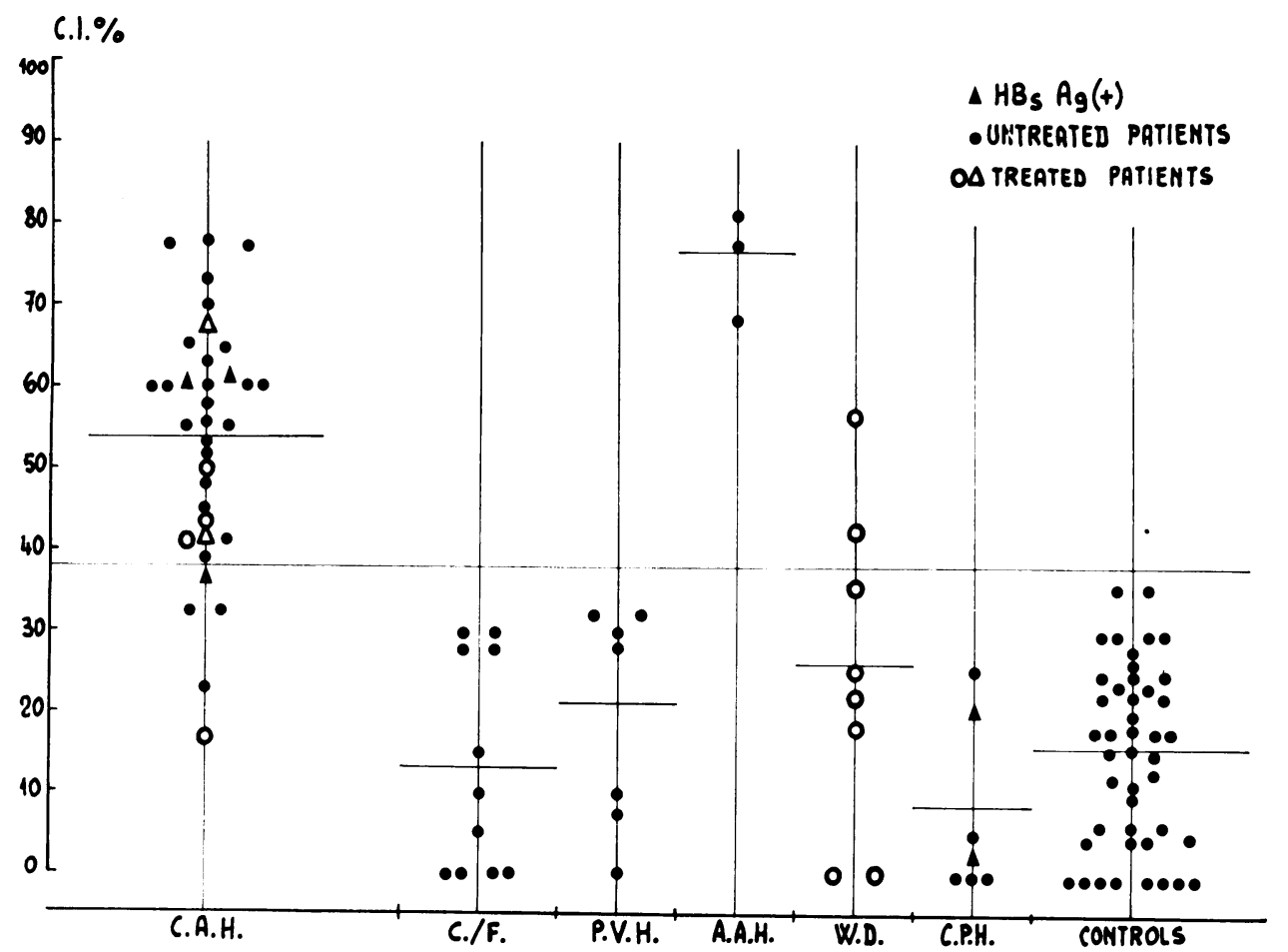

Fig. 2 Values of the cytotoxicity index $(C I \%)$ obtained from patients with various liver diseases. CAH: chronic active hepatitis. F/C: post-necrotic fibrosis and inactive cirrhosis. PVH: prolonged viral hepatitis. AAH: acute alcoholic hepatitis. WD: Wilson's disease. CPH: chronic persistent hepatitis. The lines represent the mean values of each group. CAH treated patients had received prednisolone (32 $\mathrm{mg}$ per day) for a maximum of 14 days; $W D$ received D-penicillamine (900 $\mathrm{mg}$ per day). 
three out of 35 patients with $\mathrm{CAH}$, one out of eight with cirrhosis, and one out of seven with PVH. SMA (smooth-muscle antibodies) were found in nine out of 35 patients $(25.7 \%)$ with CAH. A 'brushborder' pattern was found in three out of seven patients with CPH. The low frequency of positive autoantibodies in CAH patients did not allow any meaningful correlation with the cytotoxicity index. $\mathrm{HB}_{\mathbf{s}} \mathrm{Ag}$ was found in five with chronic active hepatitis and two with chronic persistent hepatitis. No statistically significant difference was found between the $\mathrm{CI}$ in $\mathrm{HB}_{\mathbf{s}} \mathrm{AG}$ positive and negative groups.

The patients with Wilson's disease showed a very scattered distribution of the CI with no correlation with the levels of caeruloplasmin (range = $2-15 \mathrm{mg} \%$, controls $>20 \mathrm{mg} \%$ ) and in two patients a high cytotoxicity was found $(\mathrm{CI}=42 \cdot 3$; 56.2). Six previously untreated patients with chronic active hepatitis who were under immunosuppressive therapy (6-methyl prednisolone $32 \mathrm{mg}$ per day for one month, then $16 \mathrm{mg}$ per day) were followed up, as regards their CI, for a period from five to 11 months (Fig. 3). In the group of five patients with an abnormal cytotoxicity index (CI of control $\pm 2 \mathrm{SD}$ ), four showed a decrease to normal values after two to 11 months of treatment, while the CI of one patient was increased. One

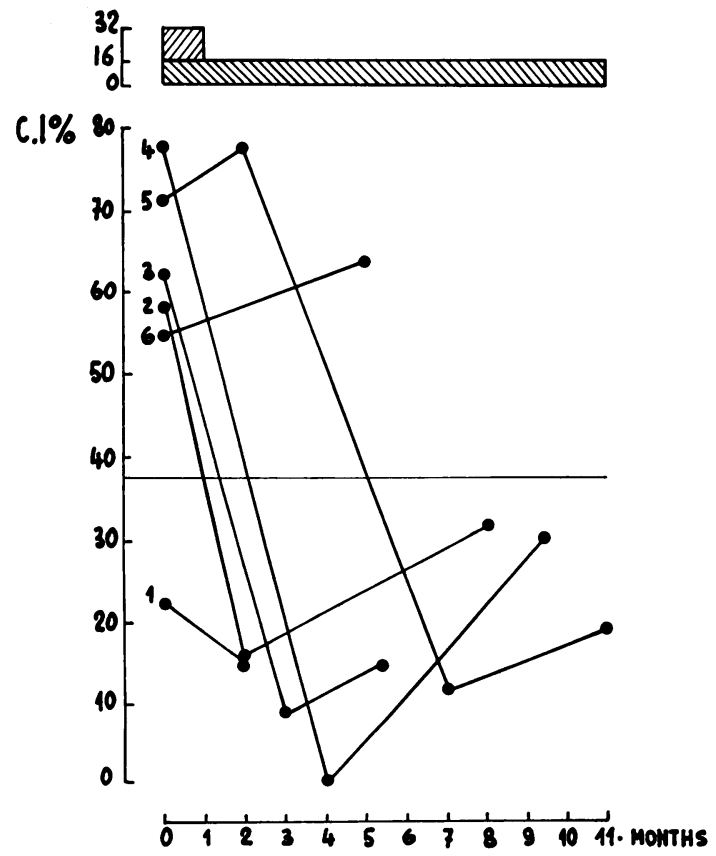

Fig. 3 Cytotoxicity index of six patients with $\mathrm{CAH}$ followed during immunosuppressive therapy. Hatched area: 6 methyl prednisolone mg/die. patient with chronic active hepatitis, with normal CI values, had only a small fluctuation of CI, always within the normal range.

Although in two subjects the behaviour of SGOT and SGPT was similar to that of CI, it was impossible to find a statistically significant correlation between the enzyme levels and the CI. After 11 months of therapy five patients showed an improvement of the histological signs of activity with a reduction of lobular infiltration and of piecemeal necrosis associated with a drop of the CI to normal levels.

The two patients with Wilson's disease and high cytotoxicity index showed signs very similar to that of a chronic active hepatitis with periportal infiltration and piecemeal necrosis.

The other six patients with Wilson's disease had only regressive lesions with glycogen vacuolisation of nuclei, lipofuscin in hepatocytes, fibrosis, but without piecemeal necrosis.

\section{Discussion}

The immunological basis of the lymphocytotoxicity test against rabbit liver cells is still obscure. A liver specific protein (LSP) seems to be antigen (Hopf et al., 1974, 1975; Thompson et al., 1974; Cochrane et al., 1976) and, at least in CAH, $\kappa$ cells (possessing the Fc receptor for IgG and the receptor for $C_{3}$ complement component) are probably involved as demonstrated by the inhibition of cytotoxicity obtained when aggregated IgG are added in the culture medium and when the lymphocytes possessing $\mathrm{C}_{3}$ complement receptors are separated on an isopycnic gradient (Cochrane et al., 1976). Monocytes, which also possess an Fc receptor, are probably not implicated, as they were removed during the purification of lymphocytes using cotton wool (Cochrane et al., 1976). To remove monocytes we used carbonyl iron treatment, with a contamination of less than $0.5 \%$ of these cells in the lymphocyte suspension, as judged by morphological observation. Although it is possible that synthesis of antibody to LSP occurs in vitro, it seems more likely that 'armed' $\kappa$ cells, carrying anti-LSP/LSP immune complexes adsorbed from the serum, may attack the membrane of isolated hepatocytes (Cochrane et al., 1976). In the type of lymphocytotoxicity test used in this study, positive results may reflect only a detachment of adherent hepatocytes from the microculture wells and not cellular death. In fact, attempts to demonstrate lysis of the hepatocytes using the release of $51 \mathrm{Cr}$, instead of the morphological technique, have not been successful because the spontaneous release of chromium was very high -up to $80 \%$.

In our study we observed very high levels of cyto- 
toxicity in the three cases of AAH. A cell-mediated immune reaction against alcoholic hyalin has been demonstrated by others (Zetterman et al., 1976) using the leukocyte migration test. Although it is difficult to relate these two phenomena, it is possible that the high cytotoxicity observed in acute alcoholic hepatitis with our system may reflect a crossreaction of activate lymphocytes against various components of rabbit hepatocyte membrane with the same antigenic structure of hyalin bodies.

Our data do not show any correlation between the $\mathrm{CI}$ and any of the biochemical parameters studied. Furthermore, in our series, the presence of autoantibodies (ANA, SMA) is very low. Other authors have obtained similar results in chronic active hepatitis (Hopf et al., 1975), and the higher frequencies of auto-antibodies found in other series (Cochrane et al., 1976) may reflect ethical differences. The high values of $\mathrm{CI}$ found in $\mathrm{CAH}$ patients with and without autoantibodies may suggest that cytotoxicity is fundamentally related to the histological appearance of piecemeal necrosis, as suggested also by the results obtained in Wilson's disease. In particular, the presence of autoantibodies may define a sub-group of CAH patients, with different genetic components and, possibly, different defects in immunological control mechanism. The presence of a high CI in the small group of $\mathrm{CAHHB}_{\mathrm{s}} \mathrm{Ag}$ positive patients (Fig. 2) is a strong indication that in these patients also there is a sensitisation against hepatocyte membrane components. In the two patients with Wilson's disease and a high CI, liver biopsies showed evident signs of activity. This suggests that, in some patients with Wilson's disease, cytotoxic sensitisation against liver cells may occur. As we have not attempted to block cytotoxicity with LSP in these patients, it is possible that antigens other than LSP are involved in the lymphocytotoxic process. The group of patients with CPH showed the lowest mean values of CI $(8.7 \pm 12.6)$; this fact agrees with the histological findings and the general good prognosis of this disease. However, we should note that the majority of the untreated patients with chronic active hepatitis, with evident histological signs of aggression, have a CI higher than the mean value of the treated group. Moreover, we have noticed a significant reduction of the CI (Fig. 3) in three patients with CAH (mean $=65 \%, \mathrm{P}<0.01$ ); after four months of immunosuppressive therapy (oral prednisolone $32+16 \mathrm{mg}$ per day) they showed a parallel improvement of histological conditions and a marked reduction of the signs of lobular infiltration and piecemeal necrosis.

Although the immunological basis of this test is not completely clear, we can conclude that it is important in evaluating cell-mediated immune activity against liver membrane antigens that may be present in diseases other than chronic active hepatitisand may be useful in evaluating the efficacy of immunosuppressive therapy.

The authors are grateful to Dr Erminia Mariani for her excellent technical assistance. This work was supported by a grant from the National Research Council (CNR).

\section{References}

Böyum A. (1968). Separation of leukocytes from blood and bone marrow. Scandinavian Journal of Laboratory and Clinical Investigation, Supp. 97.

Cochrane, A. M. G., Moussouros, A., Thomson, A. D., Eddleston, A. L. W. F., and Williams, R. (1976). Antibodydependent cell-mediated $(K$ cell) cytotoxicity against isolated hepatocytes in chronic active hepatitis. Lancet, 1, 441-444.

Eddleston, A. L. W. F., and Williams, R. (1974). Inadequate antibody response to $\mathrm{HBAg}$ or suppressor T-cell defect in development of active chronic hepatitis. Lancet, 2 , 1543-1545.

Ford, W. D., and Hunt, S. V. (1973). The preparation and labelling of lymphocytes. In Handbook of Immunology, chapter 23, edited by D. M. Weir. Blackwell: Oxford.

Hijmans, W., Schuit, H. R. E., and Klein, F. (1969). An immunofluorescence procedure for the detection of intracellular immunoglobulins. Clinical and Experimental Immunology, 4, 457-472.

Hopf, U., Meyer zum Büschenfelde, K. H., and Arnold, W. (1976). Detection of a liver-membrane autoantibody in HBsAg -negative chronic active hepatitis. New England Journal of Medicine, 294, 578-582.

Hopf, U., Arnold, W., Meyer zum Büschenfelde, K. H., Förster, E., and Bolte, J. P. (1975). Studies on the pathogenesis of chronic inflammatory liver disease. 1. Membrane-fixed IgG on isolated hepatocytes from patients. Clinical and Experimental Immunology, 22, 1-8.

Hopf, U., Meyer zum Büschenfelde, K. H., and Freudenberg, J. (1974). Liver-specific antigens of different species. II Localisation of a membrane antigen at cell surface of isolated hepatocytes. Clinical and Experimental Immuno$\log y, 16,117-124$.

Paronetto, F. and Popper, H. (1976). Two immunological reactions in the pathogenesis of hepatitis? New England Journal of Medicine, 294, 606-607.

Paronetto, F., and Vernace, S. (1975). Immunological studies in patients with chronic active hepatitis: cytotoxic activity of lymphocytes to autochthonous liver cells grown in tissue culture. Clinical and Experimental Immunology, 19, 99-104.

Roitt, I. M., and Doniach, D. (1974). Immunofluorescent Test for the Detection of Autoantibodies. Booklet 1-13. WHO: Geneva.

Thompson, A. D., Cochrane, M. A. G., McFarlane, I. G., Eddleston A. L. W. F., and Williams, R. (1974). Lymphocyte cytotoxicity to isolated hepatocytes in chronic active hepatitis. Nature (Lond.), 252, 721-722.

Zetterman, R. K., Luisada-Opper, A., and Leevy, C. M. (1976). Alcoholic hepatitis: cell -mediated immunological response to alcoholic hyalin. Gastroenterology, 70, 382-384. 